\title{
Role of Hematite Formation on Blister Generation during High Temperature Oxidation of Steel
}

\author{
Yasumitsu KONDO, ${ }^{1) *}$ Hiroshi TANEI, ${ }^{1)}$ Kohsaku USHIODA ${ }^{2)}$ and Muneyuki MAEDA ${ }^{31}$ \\ 1) Steel Rolling R\&D div., Process Technology Center, Technical Development Bureau, Nippon Steel Corporation 20-1 \\ Shintomi, Futtsu-city, Chiba, 293-8511 Japan. \\ Shintomi, Futtsu-city, Chiba, 293-8511 Japan. \\ 2) Technical Development Bureau, Nippon Steel Corporation, 20-1 \\ 3) Oita Works, Nippon Steel Corporation, 1 Oaza-Nishinosu, Oita City,
} Oita, 870-0992 Japan.

(Received on June 13, 2012; accepted on August 17, 2012)

\begin{abstract}
Blistering is a phenomenon in which oxide scale swells during oxidation at high temperatures. Blistered scale causes surface defects in steel products during hot-rolling processes. The present study investigated the effect of oxygen and the scale layer structure on blister initiation when steel is oxidized at high temperatures, and the mechanism of blister formation is discussed. The following conclusions are drawn. Blisters are not formed when the scale is a wustite mono-layer, but start to nucleate when the scale layer structure changes from the wustite mono-layer to a three-layered scale comprised of hematite $\left(\mathrm{Fe}_{2} \mathrm{O}_{3}\right)$, magnetite $\left(\mathrm{Fe}_{3} \mathrm{O}_{4}\right)$, and wustite $(\mathrm{FeO})$. The compressive stress in the oxide scale that is applied due to the oxide scale growth is largely released when scale layer structure changes from the wustite mono-layer to the three-layered scale. This result suggests that the compressive stress is not the main factor for blister initiation. It is deduced that the pressure of the $\mathrm{CO}, \mathrm{CO}_{2}$, and $\mathrm{N}_{2}$ gases generated at the scale/steel interface is the main factor for blister formation. The hematite layer on the top surface of scale presumably acts as a barrier of gas permeability.
\end{abstract}

KEY WORDS: blister; nucleation; oxygen; hematite; stress generation; gas generation; scale; oxidation.

\section{Introduction}

Surface defects are an important issue in the process of steel production. The steel surface is oxidized, and oxide scale is formed on the steel surface during the hot rolling process. The oxide scale happens to swell when the steel is oxidized at high temperature, and this phenomenon is called blistering. When scale is blistered during finishing rolling, the blistered scale causes surface defects. Two main mechanisms have been previously proposed for blistering. In one case, blistering is believed to be caused by stress generated during scale formation. ${ }^{1-4)}$ In the other case, gas generation at the scale/steel interface is thought to lead to the formation of blisters. ${ }^{1,2,5)}$ It was suggested that not only $\mathrm{CO}$ and $\mathrm{CO}_{2}$, but also $\mathrm{N}_{2}$, play a role in the blistering phenomenon. ${ }^{6,7)}$ No previous research has been reported on the role of scale structure on for blistering. Therefore, the present research is focused on the effects of the oxygen content in the atmosphere and scale structure on the blistering phenomenon. Furthermore, a stress evaluation test during oxidation was conducted in order to clarify the blistering mechanism.

\section{Experimental}

\subsection{Oxidation Test}

Steel with the chemical composition listed as No. 1 in

* Corresponding author: E-mail: kondo.x77.yasumitsu@jp.nssmc.com DOI: http://dx.doi.org/10.2355/isijinternational.52.2254
Table 1 was used for the oxidation experiments. Specimens were cut into a $30 \mathrm{~mm} \times 30 \mathrm{~mm} \times 4 \mathrm{~mm}$ rectangular shape. Oxidation was performed in an infrared furnace. The samples were heated up to the oxidation temperature in a $\mathrm{N}_{2}$ atmosphere and held for 1 hour at that temperature. This treatment gives surface nitridation before the oxidation. ${ }^{7)}$ The oxidation was initiated by changing the flowing gas from $\mathrm{N}_{2}$ to the oxidizing gas. The oxidizing conditions (temperature and atmosphere) are shown in Table 2. The purpose of the conditions A to D is to observe blistering behavior in various oxygen concentration conditions. The conditions $\mathrm{E}$ and $\mathrm{F}$ are conducted in order to clarify the effect of scale layer structure especially hematite layer formation. In these conditions the samples were firstly oxidized in low oxygen concentration atmosphere where hematite layer is not formed. The consecutive oxidations were performed in high oxygen concentration atmosphere where hematite layer is formed by changing to high oxygen concentration atmosphere. The objective of the conditions $\mathrm{H}$ and $\mathrm{I}$ is to evaluate the gas composition permeability through the oxide scale. The oxidation temperature $850^{\circ} \mathrm{C}$ in these conditions is enough below to avoid blister formation.

\subsection{Scale Growth Stress Evaluation during Scale For- mation}

In order to evaluate scale growth stress, the method to measure bending of a thin sample oxidized on one side only was used. Steel with the chemical composition listed as 
Table 1. Chemical composition of the samples [mass\%].

\begin{tabular}{cccccccc}
\hline Sample & \multicolumn{1}{c}{$\mathrm{C}$} & $\mathrm{Si}$ & $\mathrm{Mn}$ & $\mathrm{P}$ & $\mathrm{S}$ & $\mathrm{Al}$ & $\mathrm{N}$ \\
\hline 1 & 0.16 & 0.071 & 0.7 & 0.008 & 0.008 & 0.018 & 0.0032 \\
2 & 0.0081 & 0.10 & $<0.005$ & $<0.001$ & $<0.0003$ & $<0.002$ & 0.0005 \\
\hline
\end{tabular}

Table 2. Experimental conditions.

\begin{tabular}{ccrl}
\hline & & & \multicolumn{1}{c}{ Oxidation } \\
\cline { 4 - 4 } No. Sample & Temp. & \multicolumn{1}{c}{ Atmosphere and time } \\
\hline A & 1 & $1000^{\circ} \mathrm{C}$ & $\left(0.5 \% \mathrm{O}_{2}+99.5 \% \mathrm{~N}_{2}\right) \times 300 \mathrm{~s}$ \\
B & 1 & $1000^{\circ} \mathrm{C}$ & $\left(5 \% \mathrm{O}_{2}+95 \% \mathrm{~N}_{2}\right) \times 180 \mathrm{~s}$ \\
$\mathrm{C}$ & 1 & $1000^{\circ} \mathrm{C}$ & Air $\times 60 \mathrm{~s}$ \\
$\mathrm{D}$ & 1 & $1000^{\circ} \mathrm{C}$ & $\left(5 \% \mathrm{O}_{2}+95 \% \mathrm{~N}_{2}\right) \times 30 \mathrm{~s}$ \\
$\mathrm{E}$ & 1 & $1000^{\circ} \mathrm{C}$ & $\left(1 \% \mathrm{O}_{2}+31 \% \mathrm{H}_{2} \mathrm{O}+68 \% \mathrm{~N}_{2}\right) \times 180 \mathrm{~s} \rightarrow$ Air $\times 120 \mathrm{~s}$ \\
$\mathrm{~F}$ & 1 & $1000^{\circ} \mathrm{C}$ & $\left(1 \% \mathrm{O}_{2}+31 \% \mathrm{H}_{2} \mathrm{O}+68 \% \mathrm{~N}_{2}\right) \times 600 \mathrm{~s} \rightarrow$ Air $\times 120 \mathrm{~s}$ \\
$\mathrm{G}$ & 2 & $950^{\circ} \mathrm{C}$ & $\left(1 \% \mathrm{O}_{2}+31 \% \mathrm{H}_{2} \mathrm{O}+68 \% \mathrm{~N}_{2}\right) \times 300 \mathrm{~s} \rightarrow$ Air $\times 120 \mathrm{~s}$ \\
$\mathrm{H}$ & 1 & $850^{\circ} \mathrm{C}$ & $100 \% \mathrm{~N}_{2} \times 3600 \mathrm{~s} \rightarrow$ air $\times 60 \mathrm{~s} \rightarrow 100 \% \mathrm{O}_{2} \times 120 \mathrm{~s}$ \\
$\mathrm{I}$ & 1 & $850^{\circ} \mathrm{C}$ & $100 \% \mathrm{~N}_{2} \times 3600 \mathrm{~s} \rightarrow$ air $\times 60 \mathrm{~s} \rightarrow 100 \% \mathrm{Ar} \times 120 \mathrm{~s}$ \\
\hline
\end{tabular}

No. 2 in Table 1 was used to evaluate the stress generated in the oxide scale during oxidation. Specimens were cut into a $30 \mathrm{~mm} \times 5 \mathrm{~mm} \times 0.1 \mathrm{~mm}$ rectangular shape. One side of the samples was coated with a $0.7 \mu \mathrm{m}$ layer of silica in order to prevent oxidation on the surface of that side. The infrared furnace was used for the oxidation, under the conditions $G$ as listed in Table 2. Blister is not formed for this material in the conditions due to relatively high scale adhesion. The bendings of samples were observed and recorded by a camcorder.

\section{Results}

The results of the oxidation tests for conditions A to $\mathrm{C}$ are shown in Fig. 1. There are no blisters on the sample oxidized in a low oxygen concentration (condition A). However, blisters form on the samples oxidized in a relatively high oxygen concentration (conditions $\mathrm{B}$ and $\mathrm{C}$ ). The scale thicknesses for conditions $\mathrm{A}, \mathrm{B}$, and $\mathrm{C}$ are $150 \mu \mathrm{m}, 80 \mu \mathrm{m}$, and $60 \mu \mathrm{m}$, respectively, as calculated from the mass changes during the oxidations. The sample in condition A has the thickest oxide scale and no blister formation. These results suggest that the oxygen concentration has an effect on blister formation, but the scale thickness does not.

The surface appearance of the sample treated under condition D is shown in Fig. 2. Only the bottom side of the surface of the sample has blisters, while the other areas have no blisters. The bottom part of the sample is oxidized to a greater degree because the oxidant gases pass from the bottom side to the upper side in the experimental device. X-ray diffraction measurements were performed on Area 1 and Area 2 of the sample as indicated in Fig. 2. The results are indicated in Table 3. Area 1 contained wustite $(\mathrm{FeO})$ and iron $(\alpha-\mathrm{Fe})$, suggesting that the scale in Area 1 is composed of a wustite mono-layer. Meanwhile, hematite $\left(\mathrm{Fe}_{2} \mathrm{O}_{3}\right)$, magnetite $\left(\mathrm{Fe}_{3} \mathrm{O}_{4}\right)$, and wustite $(\mathrm{FeO})$ are present in Area 2, indicating that the scale in this region was a three-layered scale comprised of hematite, magnetite, and wustite. These results
Table 3. X-ray diffraction results on the areas indicated in Fig. 2 of the sample treated under condition D.

\begin{tabular}{cl}
\hline Area & \multicolumn{1}{c}{ Detected species } \\
\hline Area 1 & $\mathrm{FeO}, \alpha-\mathrm{Fe}$ \\
Area 2 & $\mathrm{Fe}_{2} \mathrm{O}_{3}, \mathrm{Fe}_{3} \mathrm{O}_{4}, \mathrm{FeO}$ \\
\hline
\end{tabular}
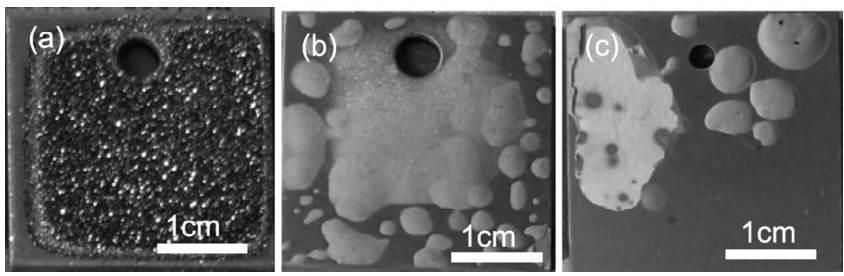

Fig. 1. Surface appearance after oxidation in various oxygen concentration atmospheres. (a) Oxidized in a $0.5 \% \mathrm{O}_{2}$ atmosphere (condition A). (b) Oxidized in a $5 \% \mathrm{O}_{2}$ atmosphere (condition B). (c) Oxidized in air (condition C).

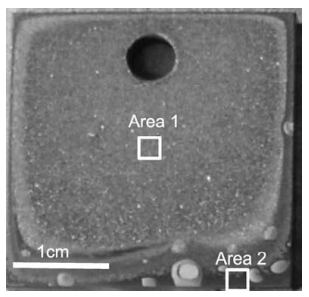

Fig. 2. Surface appearance after oxidation in a $5 \% \mathrm{O}_{2}$ atmosphere for $30 \mathrm{~s}$ (Condition D). The areas where XRD analysis was conducted are shown.
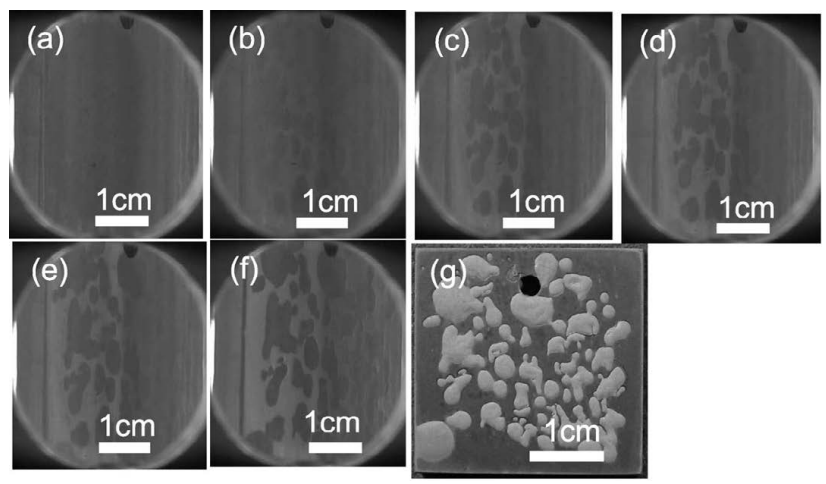

Fig. 3. Surface appearance during oxidation in air after oxidation in a $1 \% \mathrm{O}_{2}+31 \% \mathrm{H}_{2} \mathrm{O}$ atmosphere for $180 \mathrm{~s}$ (Condition $\mathrm{E}$ ). (a) Oxidized in $1 \% \mathrm{O}_{2}+31 \% \mathrm{H}_{2} \mathrm{O}$ for $180 \mathrm{~s}$. (b) Oxidized in air for $10 \mathrm{~s}$ after the atmosphere change. (c) Oxidized in air for $15 \mathrm{~s}$ after the atmosphere change. (d) Oxidized in air for $20 \mathrm{~s}$ after the atmosphere change. (e) Oxidized in air for 25 $\mathrm{s}$ after the atmosphere change. (f) Oxidized in air for $120 \mathrm{~s}$ after the atmosphere change. (g) After completion of the oxidation.

suggest that the scale layer structure has an effect on blister formation. Similar blister formation behavior was reported by Chen et al. ${ }^{8)}$

Next, the results of the experiment in order to clarify the hematite layer formation are described. The change in the surface appearance during oxidation in the furnace under condition E is shown in Figs. 3(a) to 3(f). The sample was first oxidized in an atmosphere with $1 \% \mathrm{O}_{2}+31 \% \mathrm{H}_{2} \mathrm{O}$ for 180 seconds. No blisters are formed at this stage. In order 
to verify the scale layer structure an X-ray diffraction measurement was carried out on a sample at this stage. The result shown in Table 3 indicates wustite mono-layer scale is formed. Scale with a thickness of approximately $25 \mu \mathrm{m}$ is formed, as calculated from the mass gain during the oxidation at that stage. Blisters begin to form after the atmosphere was changed to air (Figs. 3(b) to 3(f)). The three-layered scale is believed to be formed in this high oxygen concentration atmosphere. It is observed that blisters are formed over the entire surface after the oxidation (Fig. 3 (g)).

Figure 4 shows the results of the experiment conducted under condition $\mathrm{F}$. The sample was first oxidized in an atmosphere with $1 \% \mathrm{O}_{2}+31 \% \mathrm{H}_{2} \mathrm{O}$ for 600 seconds, which is about three times longer than that for condition E. Blisters are not formed at this stage. Scale with a thickness of approximately $80 \mu \mathrm{m}$ is formed as calculated from the mass gain during the oxidation. An X-ray diffraction measurement was carried out on a sample oxidized in the same low oxygen concentration condition ( $F$ in Table 4). The result shows that two-layer scale comprised of magnetite and wustite are formed at this stage. A blister begins to form and grow after the atmosphere is changed from the low oxygen concentration atmosphere to air (Figs. 4(b) to 4(f)). The results of the oxidations carried out under conditions $\mathrm{E}$ and F show that blisters are only generated on the surface of the three-layered scale structure in high oxygen concentration conditions, and are formed on neither the wustite mono-layer scale nor two-layered scale comprised of magnetite and wustite in a low oxygen concentration atmosphere.

Table 4. X-ray diffraction results on the scale formed on the samples at the situation just after oxidized low oxygen concentration atmosphere in conditions $\mathrm{E}$ and $\mathrm{F}$.

\begin{tabular}{ccl}
\hline No & \multicolumn{1}{c}{ Oxidation conditions } & Detected species \\
\hline $\mathrm{E}$ & $\left(1 \% \mathrm{O}_{2}+31 \% \mathrm{H}_{2} \mathrm{O}+68 \% \mathrm{~N}_{2}\right) \times 180 \mathrm{~s}$ & $\mathrm{FeO}$ \\
$\mathrm{F}$ & $\left(1 \% \mathrm{O}_{2}+31 \% \mathrm{H}_{2} \mathrm{O}+68 \% \mathrm{~N}_{2}\right) \times 600 \mathrm{~s}$ & $\mathrm{Fe}_{3} \mathrm{O}_{4}, \mathrm{FeO}$ \\
\hline
\end{tabular}
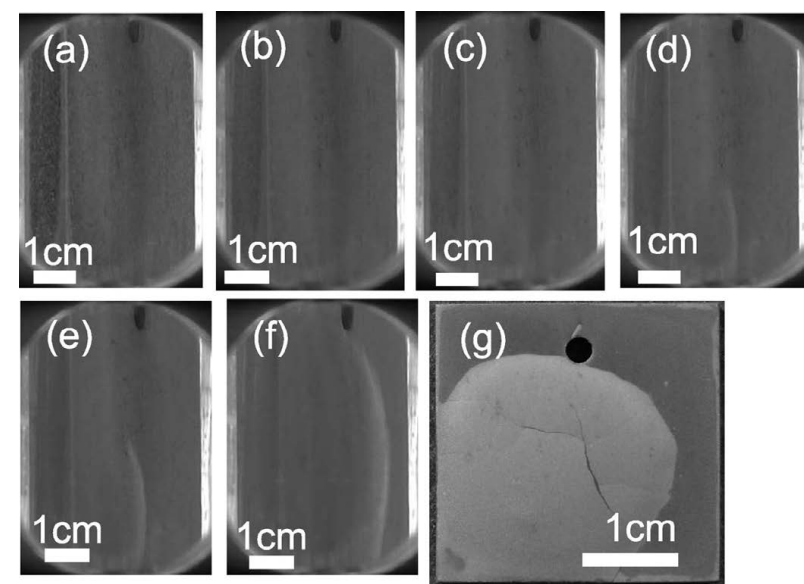

Fig. 4. Oblique views of the sample surface during oxidation in air after $600 \mathrm{~s}$ of oxidation in a $1 \% \mathrm{O}_{2}+31 \% \mathrm{H}_{2} \mathrm{O}$ atmosphere (Condition F). (a) Oxidized in $1 \% \mathrm{O}_{2}+31 \% \mathrm{H}_{2} \mathrm{O}$ for $180 \mathrm{~s}$. (b) Oxidized in air for $10 \mathrm{~s}$ after the atmosphere change. (c) Oxidized in air for $15 \mathrm{~s}$ after the atmosphere change. (d) Oxidized in air for $20 \mathrm{~s}$ after the atmosphere change. (e) Oxidized in air for $25 \mathrm{~s}$ after the atmosphere change. (f) Oxidized in air for $120 \mathrm{~s}$ after the atmosphere change. (g) After completion of the oxidation.

\section{Discussion}

As previously mentioned, two main mechanisms have been proposed for blister formation. In one case, blistering is caused by stress generated during scale formation. ${ }^{1-4)}$ In the other case, gas generated at the scale/steel interface is believed to be the cause of blistering. ${ }^{1,2,5)}$ The results of this study indicate that three-layered scale formation is necessary for blister initiation, and that no blisters are generated on wustite mono-layer scale (Figs. 3 and 4). Next, we discuss which mechanism is probable for blister initiation to explain the relationship between hematite formation and blister initiation.

\subsection{Scale Growth Stress during Oxide Formation}

Firstly, we discuss scale grow stress during oxide formation. Blisters start to form when scale structure is changed from wustite mono-layer to three-layer structure. So we focus on the scale grow stress at the situation that scale structure is changing not that at steady state oxidations. The stress generation in the scale was evaluated when the scale layer structure is changed from wustite mono-layer to three layer comprised of hematite, magnetite, and wustite. This test was conducted under condition $\mathrm{G}$ in Table 2 . The side views during oxidation are shown in Fig. 5. The sample was first oxidized in a low oxygen concentration atmosphere of $1 \% \mathrm{O}_{2}+31 \% \mathrm{H}_{2} \mathrm{O}$ for 300 seconds. The sample is slightly bent toward the side of the non-oxidizable surface (Fig. 5(b)). Compressive stress is applied in the wustite monolayer scale. However, the curvature of the sample decreased after the atmosphere was changed to air (Fig. 5(c)). This result indicates that the compressive stress in the scale is mostly released during the change of the scale structure from a wustite mono-layer to a three-layered scale. Therefore, these results indicate that the compressive stress when blister formation is initiated is very low, and is not a major factor in blister formation. After further oxidation in air, the sample is gradually bent (Fig. 5(d)) toward the side of the (a)

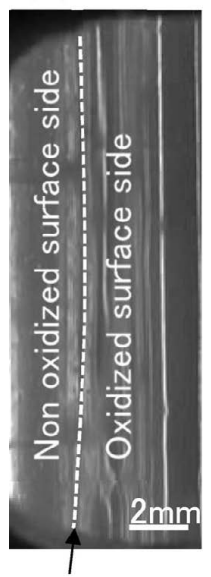

Sample
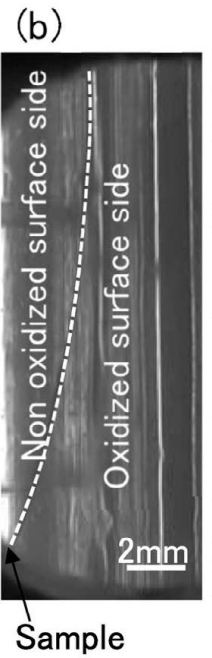

(c)

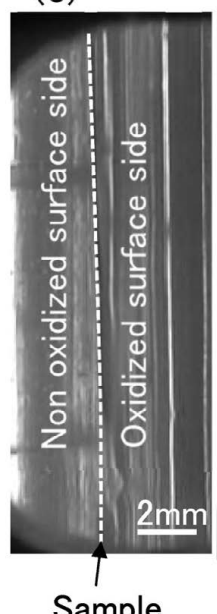

Sample (d)

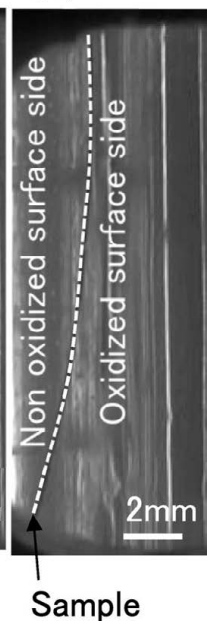

Fig. 5. Side views of thin specimens during oxidation using condition G. (a) Before oxidation. (b) Oxidized in a low $\mathrm{O}_{2}$ concentration atmosphere for $300 \mathrm{~s}$. (c) Oxidized in air for $11 \mathrm{~s}$ after changing from the low $\mathrm{O}_{2}$ concentration atmosphere. (d) Oxidized in air for $120 \mathrm{~s}$ after changing from the low $\mathrm{O}_{2}$ concentration atmosphere. 
non-oxidized surface, indicating that a compressive stress is once again building within the scale. Thus, it is difficult to explain blister initiation by the grow stress mechanism.

The decrease in the compressive stress as the scale structure changes from wustite mono-layer scale to three-layered scale is explained by the composition change of the wustite. Wustite has a wide range of non-stoichiometric composition, and the lattice constant of wustite depends on the nonstoichiometry. ${ }^{9)}$ The $x$ value when the composition of wustite is expressed as $\mathrm{Fe}_{1-\mathrm{x}} \mathrm{O}$ is relatively small and the size of the wustite lattice is larger when the scale is a wustite monolayer, because the wustite scale forms in a lower oxygen potential situation. On the other hand, the $x$ value becomes larger and the lattice size of the wustite becomes smaller when the scale is a three-layered structure, because the wustite is in a higher oxygen potential situation. Thus, the compressive stress applied in the scale decreases when the scale layer structure changes from a wustite mono-layer to a three-layered scale.

\subsection{Gas Generated at the Scale/Steel Interface}

Next, we discuss gas generated at the scale/steel interface. Our previous research indicates that $\mathrm{CO}, \mathrm{CO}_{2}$, and $\mathrm{N}_{2}$ gases are main gaseous composition in a blister at the initiation stage and the gas pressure generated there is possible to detach the scale from the steel. ${ }^{6}$ At the growth stage of blister, $\mathrm{N}_{2}$ alone was also found to have an effect on blister growth. ${ }^{7)}$ These results suggest that the pressure of the $\mathrm{CO}$, $\mathrm{CO}_{2}$, and $\mathrm{N}_{2}$ gases generated at the scale/steel interface has a significant influence on blister initiation. We assume that spaces are already formed at the scale/steel interface before blister initiation. Figure 6(a) shows a magnified scale/steel interface of the sample oxidized in air at $950^{\circ} \mathrm{C}$ for $120 \mathrm{~s}$.

(a)

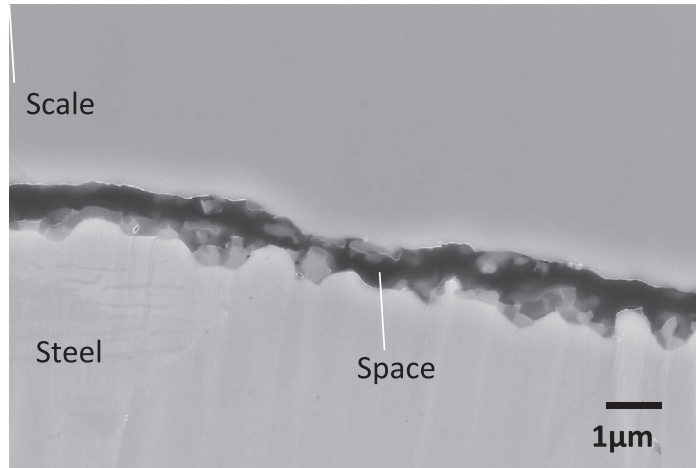

(b)

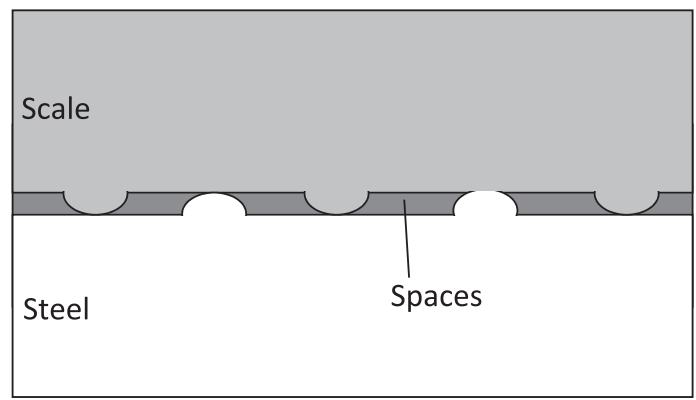

Fig. 6. Scale/steel interface. (a)SEM image of the scale/steel interface of the sample oxidized $950^{\circ} \mathrm{C}$ for $120 \mathrm{~s}$. There are spaces at the scale/steel interface. The scale is well adhered. (b) Schematic image of scale/steel interface. There some points to contact with each other.
There are some spaces at the scale/steel interface although the scale is well adhered. Figure 6(b) shows a schematic image of the scale/steel interface. It is assumed that scale contacts with steel at some small points. Gas pressures of $\mathrm{CO}, \mathrm{CO}_{2}$, and $\mathrm{N}_{2}$ generated at the scale/steel interface accumulate the spaces and tend to separate the scale from the steel.

Gas permeability through the oxide scale is thus important. It is necessary to verify that the wustite mono-layer scale has a high permeability, and that the three-layered scale, the hematite on the top surface, presumably has a low permeability according to the difference in blistering behavior between the three-layered and the wustite mono-layered scale. In order to verify the gas permeability, oxidation tests of condition $\mathrm{H}$ and I were performed. Glow-discharge optical emission spectroscopy (GD-OES) measurements on the surfaces of the samples oxidized under conditions $\mathrm{H}$ and I are shown in Figs. 7(a) and 7(b), respectively. The oxide scale formed on the sample first oxidized in an air atmosphere and then held in a $100 \% \mathrm{O}_{2}$ atmosphere (condition $\mathrm{H}$ ) is thought to be the three-layered scale, because of the high oxygen concentration. The scale for this sample contained gaseous component of $\mathrm{N}$ near the scale/steel interface after the oxidation (Fig. 7(a)).

On the other hand, for the sample oxidized in air and then held in an Ar atmosphere (condition I) the oxide scale is thought to be changed from the three-layered scale to the wustite mono-layer structure under the Ar atmosphere because there is substantially no oxygen. ${ }^{10)}$ The gaseous element of $\mathrm{N}$ is mostly disappears when the sample is held in an $\mathrm{Ar}$ atmosphere (Fig. 7(b)). Nitrogen is supposed to be released to the atmosphere. The results of the nitrogen dis-
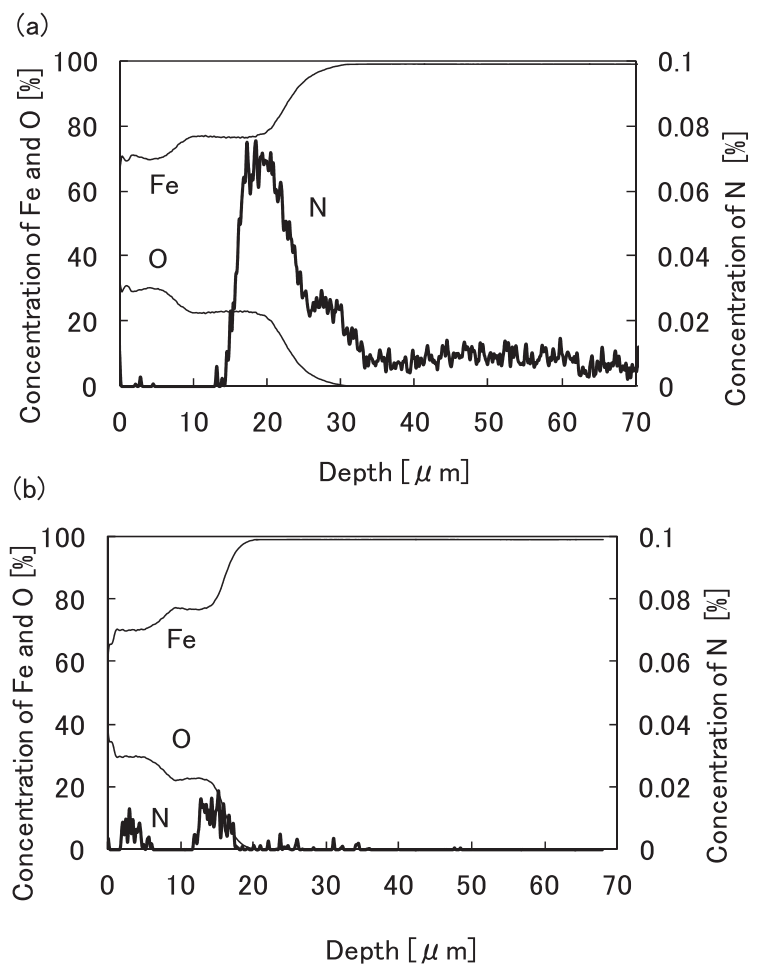

Fig. 7. GD-OES measurement results after oxidation. (a) Oxidized in an $\mathrm{O}_{2}$ atmosphere for $120 \mathrm{~s}$ after oxidation in air for $600 \mathrm{~s}$ (Condition H). (b) Held in an Ar atmosphere for $120 \mathrm{~s}$ after the oxidation in air for $600 \mathrm{~s}$ (Condition I). 
tribution tests shown in Fig. 7 experimentally indicate that nitrogen permeability greatly depends on the scale layer structure. The oxygen concentration at the surface in Fig. 7(b) is higher than that of inner part. This is due to the oxidation when the sample was taken out from the furnace. It is considered that hematite layer is not formed at $850^{\circ} \mathrm{C}$ in the $\mathrm{Ar}$ atmosphere because hematite is not stable and the hematite is reduced to magnetite or wustie in that atmosphere with substantially no oxygen concentration.

In addition, it is known that decarburization of steel takes place underneath the scale formed on steel surfaces. ${ }^{11)}$ Decarburization reaction produces $\mathrm{CO}$ and $\mathrm{CO}_{2}$, which migrate through the oxide scale, making it possible for the decarburization reaction to continue. It is assumed that these gases pass through micro-cracks or fissures in the scale. ${ }^{11)}$ However, these microstructures were not observed in the oxide scale in this study. Further research is therefore necessary on the dependence of the scale structure on the gas permeability.

\subsection{Effects of Temperature and Oxidation Time on Blister Generation}

The effect of temperature on blister initiation time is discussed. Matsuno indicated that higher oxidation temperature has longer blistering initiation time shown in Fig. 8. ${ }^{3)} \mathrm{He}$ thought that growth stress is main factor and explained the temperature effect by the relationship between scale adhesive force and scale growth stress. Here, it unlikely that scale growth stress cause blister initiation. It seems that gas pressure generated at the scale/steel interface is more prob-

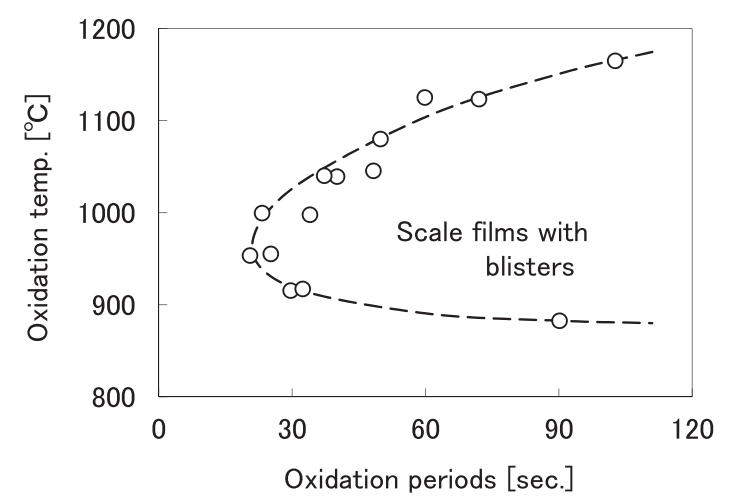

Fig. 8. The relationship between blister initiation time and oxidation temperature during the isothermal oxidation. ${ }^{3)}$

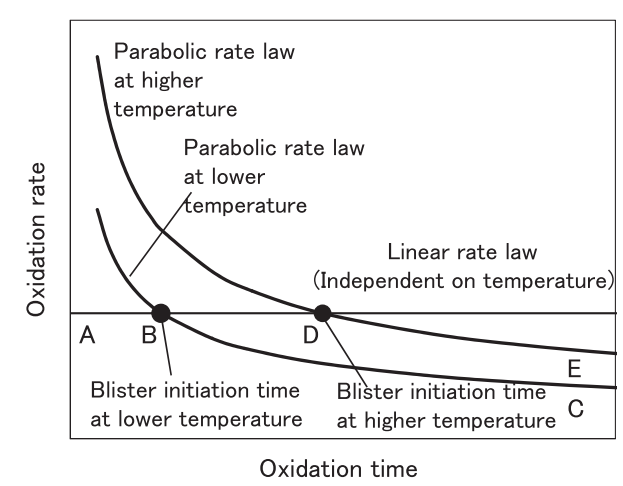

Fig. 9. The relationship between parabolic rate law and linear rate law. Blister initiates at the point when the kinetics changes from the linear rate law to the parabolic rate law. able mechanism. Here, we try to explain the relationship between temperature and blister initiation time.

The effects of temperature and oxidation time on blister generation are explained by the scale growth mechanism. The blister generation time depends on the change in the scale structure. The results in this study revealed that blisters start to form when the scale structure changes from a wustite mono-layer to a three-layered scale with hematite, magnetite, and wustite. The scale formation follows a parabolic rate law and results in a three-layered structure in the case when iron ion diffusion through the oxide scale is the rate determining step. Therefore the oxidation rate under the parabolic behavior depends on temperature. On the other hand, scale formation follows a linear rate law and results in a wustite mono-layer structure when oxygen gas diffusion to the steel surface limits the oxidation rate. ${ }^{12,13)}$ In this linear rate law region oxidation rate almost independent on temperature. ${ }^{13,14)}$ The relationship between the parabolic rate law and the linear rate law is shown in Fig. 9. Slower oxidation rate law controls the oxidation rate. An oxidation rate follows the linear rate law at first. Then it is controlled by the parabolic rate law. For example, the oxidation rate follows the route of A-B-C in Fig. 9 at lower temperature and the oxidation rate does the route of A-D-E in Fig. 9 at higher temperature. Scale structure is also changed at the transition time from wustite mono-layer scale to three- layer scale. Blister initiation time is the transition time from the linear rate law to the parabolic rate law. Thus, the graph indicates the condition with higher temperature has longer blister initiation time.

The effect of temperature on blister formation is considered to be related to the scale adhesion force. The force required to detach various oxide scales were measured and are shown in Fig. 10. ${ }^{\text {) }}$ The adhesive force is lower for scales formed at higher temperatures. Under these conditions, $\mathrm{CO}, \mathrm{CO}_{2}$, and $\mathrm{N}_{2}$ gases tend to be generated underneath the scale. The presence of the gases is related to blister nucleation. The pressure of the $\mathrm{CO}$ and $\mathrm{CO}_{2}$ are high enough to cause the scales to detach. ${ }^{6}$ ) Formation of blisters is initiated when the gas pressure underneath the oxide scale exceeds the scale adhesion force.

The relationship between the blister initiation time and the temperature is schematically summarized in Fig. 11. The blister initiating time is the time that hematite layer is start to be formed. It is equal to the transition time from the linear rate law to the parabolic rate law. As explained in Fig. 9, the

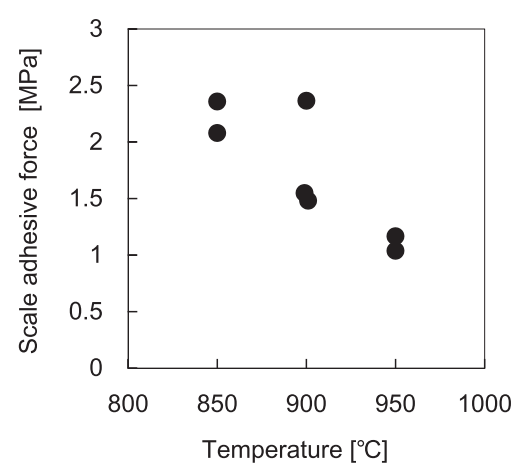

Fig. 10. Relationship between the scale adhesive force and the temperature. ${ }^{6}$ 


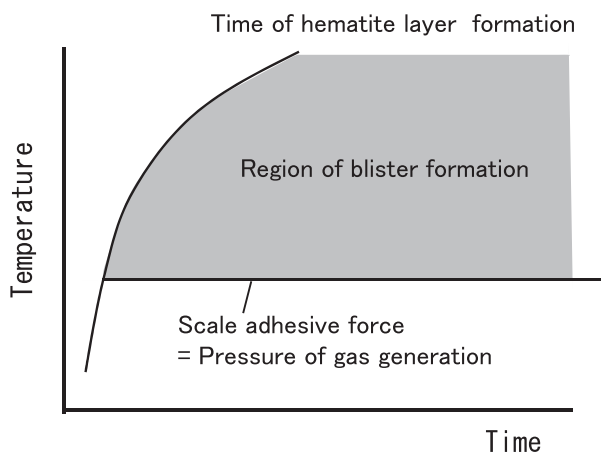

Fig. 11. Schematic image of the relationship between the blister initiation time and the temperature.

blister initiation time is longer at higher temperature. The critical temperature of blister formation is the temperature that the gas pressure, which should be $\mathrm{CO}, \mathrm{CO} 2$, and $\mathrm{N}_{2}$, underneath the oxide scale, exceeds the scale adhesion force. ${ }^{6}$ The authors also discussed that the blister formation condition is limited by scale adhesion force rather than scale deformability because the adhesive force is lower than the yield strength of wustite at high temperature. ${ }^{6)}$ Above the temperature gas pressure beneath the scale exceeds the scale adhesive force because scale adhesive force become low at higher temperature as Fig. 10 shows.

Blister initiating behavior observed in this study is schematically summarized in Fig. 12. Blisters are not formed at the initial stage of oxidation, where oxidation rate is followed by liner rate low and only wustite mono-layer scale is formed (Fig. 12(a)). In this stage gases of $\mathrm{CO}, \mathrm{CO}_{2}$ and $\mathrm{N}_{2}$ generated beneath the scale go out along the paths such as micro pores through the scale and no blisters are formed. During the transient from the region of the linear rate law to that of the parabolic rate law, two-layer scale comprised of magnetite and wustite is formed. The gases of $\mathrm{CO}, \mathrm{CO}_{2}$ and $\mathrm{N}_{2}$ also can migrate through the scale and blisters are not formed at this stage (Fig. 12(b)). This situation is observed in Fig. 4(a). However, this stage lasts only for short period. The oxidation is soon followed by the parabolic rate law and three-layer scale comprised of hematite, magnetite, and wustite is formed. The hematite layer has low gas permeability and the gas pressure beneath the scale increases. At this moment blisters start to be formed (Fig. 12(c)). The main factor to blister inflation is supposed to be by gas pressure generated at the scale/steel interface.

\section{Conclusions}

The effects of oxygen concentration and scale structure on blister initiation behavior during oxidation of steel at high temperatures were investigated. The following conclusions are drawn:

(1) Blisters do not form when the scale has a wustite mono-layer structure.

(2) Blisters start to nucleate when the scale layer structure changes from a wustite mono-layer to a three-layered scale consisting of hematite, magnetite, and wustite.

(3) Compressive stress applied in the oxide scale is
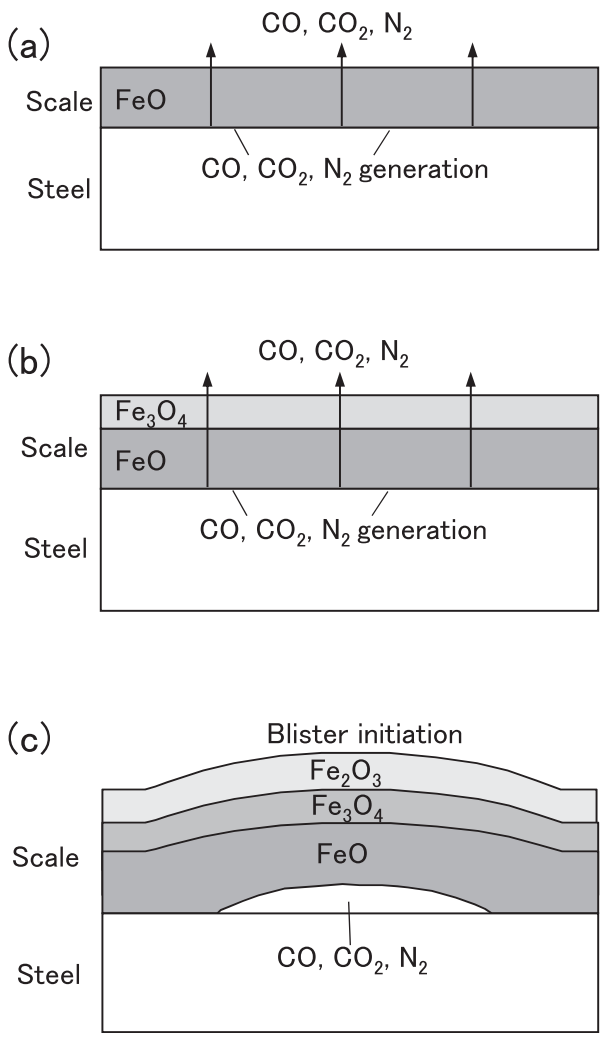

Fig. 12. Schematic image of the blister initiation mechanism. The arrows show the gas flow of $\mathrm{CO}, \mathrm{CO}_{2}$, and $\mathrm{N}_{2}$. They are generated at the scale/steel interface. (a) Initial stage of oxidation. The scale is the wustite mono-layer type. (b) A two-layered scale comprised of magnetite, and wustite is formed. (c) A three-layered scale comprised of hematite, magnetite, and wustite is formed. The blister is initiated.

mostly released when the scale layer structure changes from a wustite mono-layer to a three-layered scale consisting of hematite, magnetite, and wustite. This result suggests that compressive stress is not a main factor for blister initiation.

(4) It is deduced that the pressure of the $\mathrm{CO}, \mathrm{CO}_{2}$, and $\mathrm{N}_{2}$ generated at the scale/steel interface is a main factor in blister nucleation and growth, and that the hematite on the top surface of scale presumably acts as a barrier against gas permeation.

\section{REFERENCES}

1) R. Griffith: Heat Treating Forging, 20 (1934), 447.

2) R. Rolls: Metallurgie, VII (1967), 53

3) F. Matsuno: Trans. Iron Steel Inst. Jpn., 20 (1980), 413.

4) T. Kizu, Y. Nagataki, T. Inazumi and Y. Hosoya: ISIJ Int., 41 (2001), 1494.

5) S. Modin and E. Tholander: Metal Treat., 28 (1961), 261.

6) Y. Kondo, H. Tanei, N. Suzuki, K. Ushioda and M. Maeda: ISIJ Int., 51 (2011), 1696.

7) Y. Kondo, H. Tanei, K. Ushioda, M. Maeda and Y. Abe: ISIJ Int., 52 (2012), in press.

8) R. Y. Chen and W. Y. D. Yuen: Oxid. Met., 70 (2008), 39.

9) P. K. Foster and A. J. Welch: Trans. Faraday Soc., 52 (1956), 1926.

10) R. Y. Chen and W. Y. D. Yuen: Oxid. Met., 56 (2001), 89.

11) N. Birks and G. H. Meier: Introduction to High Temperature Oxidation of Metals, Edward Arnold, London, (1983), 175.

12) H. T. Abuluwefa, R. I. L. Guthrie and F. Ajersch: Metall. Mater. Trans. A, 28A (1997), 1633.

13) H. T. Abuluwefa, R. L. L. Guthrie and F. Ajersch: Oxid. Met., 46 (1996), 423.

14) A. Rahmel: Werkstoffe Korrosion, 23 (1972), 95. 